\title{
Jejunal intraepithelial lymphocytes in coeliac disease: are they increased or decreased?
}

\author{
G R CORAZZA, M FRAZZONI, AND G GASBARRINI
}

From the III Department of Medical Pathology, Policlinico S. Orsola, Bologna University, Bologna, Italy

SUMmARY We have quantified intraepithelial lymphocytes in the same biopsy series (21 healthy controls, 14 untreated coeliacs, 15 treated coeliacs, five non-coeliac patients with an abnormal jejunal mucosa) both as counts/100 epithelial cells and using as reference value a fixed area of muscularis mucosae. As expected, the number of intraepithelial lymphocytes/100 epithelial cells was significantly higher in untreated and treated coeliacs than in healthy controls, as well as in untreated when compared with treated coeliac patients. Otherwise, the number of intraepithelial lymphocytes lying in the area of mucosal surface overlying a fixed area of muscularis mucosae was significantly lower in treated and untreated coeliacs, than in healthy controls, as well as in untreated when compared with treated coeliacs. A highly significant inverse correlation was found between the number of intraepithelial lymphocytes/100 epithelial cells and the mucosal surface area measured as surface to volume ratio. When the number of intraepithelial lymphocytes/100 epithelial cells was corrected for differences in surface to volume ratio, the results were very similar to those obtained by a muscularis mucosae related count. In five coeliacs both intraepithelial lymphocyte and enterocyte muscularis mucosae related counts rose after a period of gluten free diet but the mean per cent increase of enterocytes was significantly higher than that of lymphocytes. Our results are compatible with a decrease in the total number of intraepithelial lymphocytes in the entire small bowel in coeliac disease. In untreated coeliac mucosae, however, a derangement in the usual proportions of intraepithelial lymphocytes and enterocytes is evident and may be important in the pathogenesis of coeliac disease.

The increased number of lymphocytes lying within the jejunal epithelium of untreated coeliac mucosa has been quoted over the years in support of an immunological explanation for the action of gluten. ${ }^{1-4}$ Previous methods of measuring intraepithelial lymphocytes, however, namely the number/100 epithelial cells or those found in a given length of the epithelial layer have been recently criticised $^{56}$ as the reference value for the measurement is severely altered in coeliac disease.

We have therefore quantified intraepithelial lymphocytes in the same biopsy series both as counts/100 epithelial cells and using as reference value a fixed area of muscularis mucosae.

\section{Methods}

JEJUNAL BIOPSIES

Proximal jejunal biopsies were obtained, as part of

Address for correspondence: Dr G R Corazza, III Patologia Medica, Policlinico S. Orsola, Via Massarenti 9,40100, Bologna, Italy.

Received for publication 14 April 1983 the routine diagnostic procedure, from 14 adult untreated coeliac patients, 15 adult coeliac patients on a gluten free diet, and five other patients with an abnormal jejunal mucosa (two Whipple's disease, one dermatitis herpetiformis, one Crohn's disease, and one blind-loop syndrome), called 'abnormal controls'. As healthy controls, biopsies were taken from 21 subjects complaining of abdominal symptoms, but in whom detailed investigations showed no evidence of small bowel disease.

After preliminary orientation using a dissecting microscope, sections $4 \mu \mathrm{m}$ thick were prepared stained with haematoxylin and eosin and examined microscopically (Leitz Dialux 20 , under $\times 100$ oilimmersion objective).

QUANTITATIVE HISTOLOGY

Intraepithelial lymphocytes were measured (a) by a differential count of at least 500 cell nuclei (epithelial and lymphocyte) and the results expressed as intraepithelial lymphocytes/100 epithelial cells, ${ }^{1}$ and (b) by counting the total 
number of intraepithelial lymphocytes lying in an area of mucosal surface overlying a fixed area of muscularis mucosae. ${ }^{6}$ Using an ocular linear graticule, lymphocytes were counted in the surface epithelium overlying an area of muscularis mucosae defined by the length of the graticule $(60 \mu \mathrm{m})$ and the thickness of the section $(4 \mu \mathrm{m})$. Fifteen such areas were counted to give a total area of $3600 \mu \mathrm{m}^{2}$, called the 'test area'. Only one out of three adjacent sections was studied to ensure that no cell was counted twice. In order to verify a possible relationship between intraepithelial lymphocyte counts/100 epithelial cells and a reduction in the area of surface epithelium, we related our counts to the measurement of surface to volume ratio. ${ }^{7}$ The mean and range of surface to volume ratio for the four groups of patients studied are shown in the Table. In five coeliac patients we also measured the number of lymphocytes and enterocytes in the test area before and after a gluten free diet (mean duration of the diet: six months).

\section{STATISTICS}

The results were analysed by the Wilcoxon's rank sum test for unpaired data and by the Spearman's rank correlation test.

\section{Results}

Intraepithelial lymphocyte counts/100 epithelial cells are shown in Fig. 1. The number of intraepithelial lymphocytes was significantly higher in treated and untreated coeliacs than in healthy controls, as well as in untreated when compared with treated coeliacs. No difference was observed between abnormal controls and both coeliacs and healthy controls. The upper value of the control range was $34 \cdot 1 / 100$ epithelial cells. All the coeliacs on a gluten containing diet were above this value, as were 11 out of 15 treated coeliacs and three out of five abnormal controls.

Intraepithelial lymphocyte counts per test area are shown in Fig. 2. The number of intraepithelial lymphocytes was significantly lower in treated and untreated coeliacs than in healthy controls, as well as in untreated when compared with treated coeliacs. No difference was observed between

Table Surface to volume ratio for four groups of patients

\begin{tabular}{lcc}
\hline & Mean & Range \\
\hline Untreated coeliacs & $9 \cdot 0$ & $2 \cdot 6-15 \cdot 6$ \\
Treated coeliacs & $24 \cdot 8$ & $7 \cdot 4-44 \cdot 8$ \\
Abnormal controls & $25 \cdot 3$ & $1 \cdot 3-47.4$ \\
Healthy controls & $91 \cdot 1$ & $59 \cdot 2-140 \cdot 5$ \\
\hline
\end{tabular}

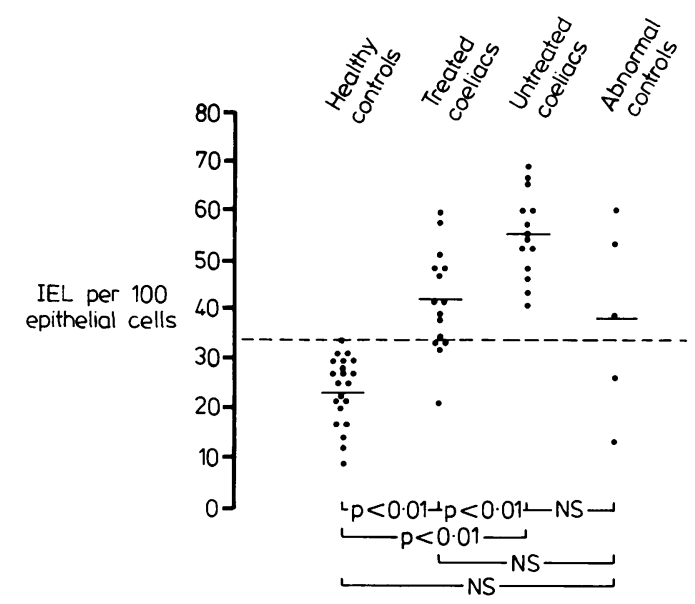

Fig. 1 Intraepithelial lymphocyte (IEL) counts/100 enterocytes.

abnormal controls and both coeliacs and healthy controls. The lowest value of the control range was 65.0 intraepithelial lymphocytes per test area.

The number of intraepithelial lymphocytes $/ 100$ epithelial cells plotted against the surface to volume ratio is shown in Fig. 3. There was a significant inverse correlation between these two parameters. We then corrected the number of intraepithelial lymphocytes/100 epithelial cells for the surface to volume ratio according to the formula

intraepithelial lymphocytes $\times$ observed surface to volume ratio

control surface to volume ratio

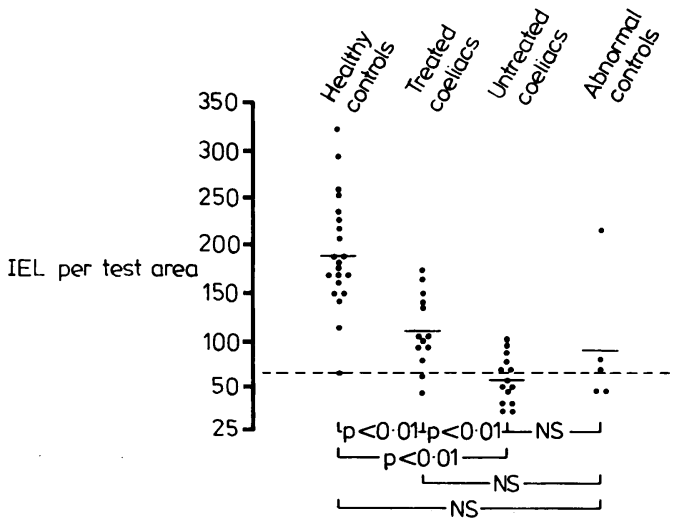

Fig. 2 Intraepithelial lymphocyte (IEL) counts per area of mucosal surface overlying a fixed area of muscularis mucosae. 


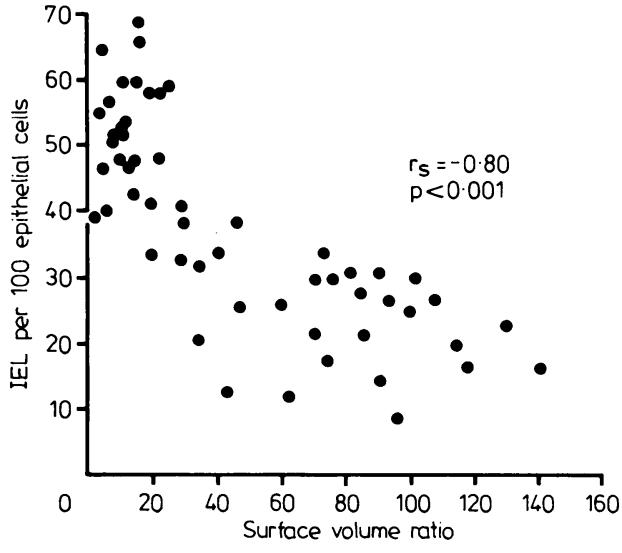

Fig. 3 Correlation between number of intraepithelial lymphocytes (IEL)/100 epithelial cells and surface to volume ratio in 55 jejunal biopsies.

where the control surface to volume ratio was the mean value obtained in the healthy control group. The number of intraepithelial lymphocytes $/ 100$ epithelial cells corrected using this formula is shown in Fig. 4. The number of intraepithelial lymphocytes was significantly lower in treated and untreated coeliacs and in abnormal controls than in healthy controls. Levels in untreated coeliacs were significantly lower than in coeliacs on a gluten free diet but there was no difference between abnormal controls and both the groups of coeliacs.

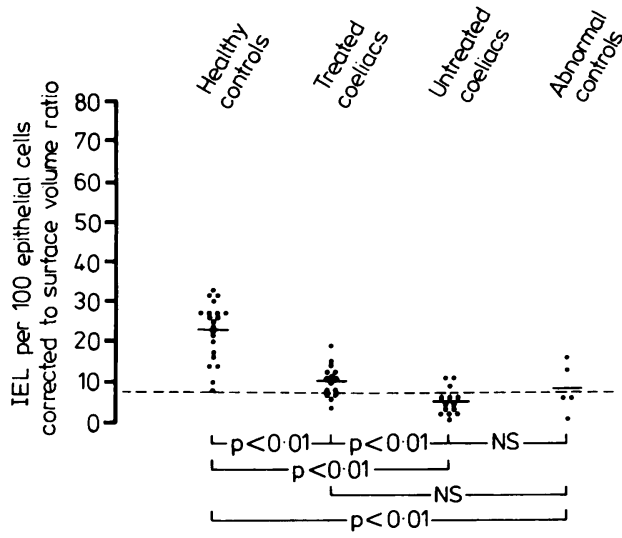

Fig. 4 Intraepithelial lymphocyte (IEL) counts/100 epithelial cells corrected for differences in surface to volume ratio.
In five coeliac patients the number of intraepithelial lymphocytes and enterocytes per test area was counted before and after gluten free diet. The results are shown in Fig. 5. Both the parameters rose after treatment but the mean per cent increase, calculated according to the formula $\frac{\text { no of cells after diet }- \text { no of cells before diet }}{\text { no of cells after diet }} \times 100$,

of the enterocytes $(60.4)$ was significantly higher than that of lymphocytes $(37.9) \quad(p<0.02)$. Moreover, the mean intraepithelial lymphocytes to enterocytes ratio before gluten free diet $(0 \cdot 55)$ was significantly higher $(\mathrm{p}<0.02)$ than after diet $(0.36)$.

\section{Discussion}

We have confirmed the apparent increase in intraepithelial lymphocytes which occurs both in untreated and treated coeliacs by counting their number/100 epithelial cells. ${ }^{1}$

By counting intraepithelial lymphocytes in a surface epithelial area defined by a fixed area of muscularis mucosae we confirmed their decrease in untreated coeliacs as found by Marsh, ${ }^{6}$ but also found a significant decrease in treated coeliac disease, which diverges from Marsh's findings. Nevertheless, in Marsh's series intraepithelial lymphocyte values in treated patients were lower than in controls and the lack of significance might perhaps be because of the small number of cases (four) studied. Guix et $a l,{ }^{5}$ who also used a

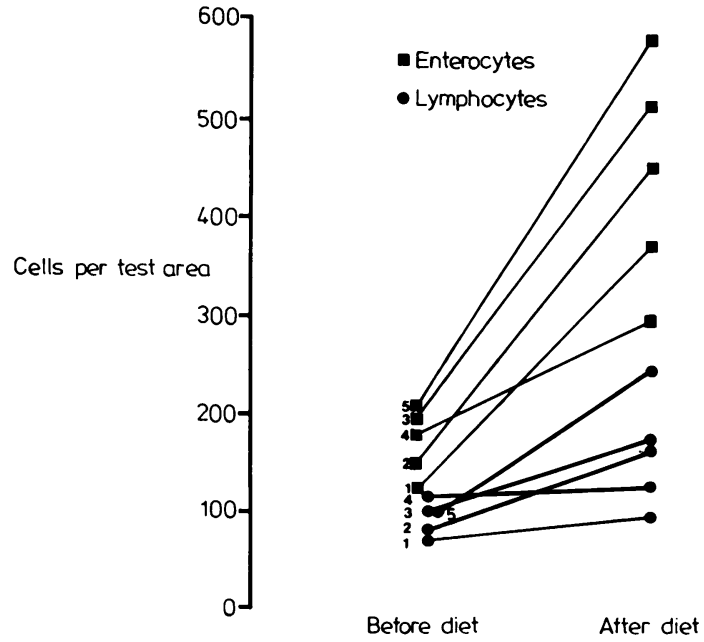

Fig. 5 Intraepithelial lymphocyte and enterocyte muscularis mucosae related counts in five coeliac patients before and after gluten free diet. 
muscularis mucosae related count, did not find any difference in intraepithelial lymphocyte number between coeliacs and controls. The discrepancy between their results and our finding of decreased intraepithelial lymphocytes in coeliac disease may be only apparent and might be ascribed to their counting of lymphocytes within crypt epithelium which is hyperplastic in coeliac disease.

Thus, by both methods a good separation between coeliacs and healthy controls was obtained, confirming that both may be useful in diagnostic pathology. As the results obtained by these two methods of counting are diametrically opposed, however, the question as to whether or not intraepithelial lymphocytes are actually increased or decreased in coeliac mucosa remains to be clarified. It has been suggested that in coeliac mucosa intraepithelial lymphocytes are merely crowded as a result of reduction in surface area. ${ }^{6}$ Although previous papers have not shown a correlation between intraepithelial lymphocyte count and the severity of villous atrophy assessed subjectively, ${ }^{89}$ the comparison of intraepithelial lymphocytes with surface to volume ratio has provided more contrasting results. A significant correlation was found by Glasgow et al,$^{10}$ while De Peyer et al ${ }^{11}$ comparing the two parameters found a virtually random distribution. Our findings show a highly significant inverse correlation between the number of intraepithelial lymphocytes/100 epithelial cells and surface to volume ratio, and by correcting the former parameter for differences in surface to volume ratio, the results were very similar to those obtained using a muscularis mucosae related count of intraepithelial lymphocytes. Nevertheless, we cannot conclude that in coeliac disease the apparent increase of intraepithelial lymphocytes is merely a direct consequence of diminished surface area: a third phenomenon, for instance gluten intake, may well be responsible for both changes. Using the muscularis mucosae related counts, our results and those of Marsh are compatible with a decrease in the total number of intraepithelial lymphocytes in the entire small bowel in coeliac disease but we agree with Ferguson's suggestion that their immunological or clinical relevance may be related 'to the microenvironment in a single villous or at an even smaller scale in the villous epithelium' ${ }^{3}$ In untreated coeliac disease an enhanced luminal loss of enterocytes ${ }^{12} 13$ as well as of lymphocytes ${ }^{14}$ has been described. Accordingly our coeliac patients show a significant increase of both cell populations per test area after gluten withdrawal. Moreover, the mean per cent increase of the enterocytes was significantly higher than that of lymphocytes, showing that the sizes of the two populations vary with treatment at different rates. In untreated coeliac mucosa the number of intraepithelial lymphocytes per test area, although reduced as a likely consequence of luminal loss ${ }^{14}$ is significantly closer to the number of enterocytes than in coeliacs after treatment. Therefore, if we relate our counts to a microenvironment in untreated coeliac mucosa, a disproportion between intraepithelial lymphocytes and enterocytes is evident, namely a relative increase, or a lesser decrease, or more likely both, of intraepithelial lymphocytes versus enterocytes.

Blast transformation of intraepithelial lymphocytes reversed by gluten withdrawal, occurs in active coeliac disease 6 and this phenomenon has been considered to be a result of luminal antigenic stimulation. ${ }^{15}$ This suggests that intraepithelial lymphocytes, which have been recently characterised by monoclonal antibodies as $\mathrm{T}$ cells ${ }^{16}$ with suppressor/cytotoxic phenotype, ${ }^{17}$ are an activated population in untreated coeliac mucosa.

In conclusion, our data, even though in agreement with Marsh $^{6}$ as far as a global decrease of intraepithelial lymphocytes in the entire small bowel is concerned, show that in untreated coeliac mucosa there is a derangement in the usual proportions of intraepithelial lymphocytes and enterocytes. We suggest that this imbalance is important in the local immune reaction to gluten in coeliac disease.

This work was presented in part at the National Meeting of the Italian Society of Gastroenterology, Genova, Italy, November 1982.

The authors are grateful to Dr M F Dixon, Department of Pathology, University of Leeds, United Kingdom, for his critical review, and to Mr Nunzio Salfi for technical assistance.

\section{References}

1 Ferguson A, Murray D. Quantitation of intraepithelial lymphocytes in human jejunum. Gut 1971; 12: 988-94.

2 Holmes GKT, Asquith P, Stokes PL, Cooke WT. Cellular infiltrate of jejunal biopsies in adult coeliac disease in relation to gluten withdrawal. Gut 1974; 15: 278-83.

3 Ferguson A. Intraepithelial lymphocytes of the small intestine. Gut 1977; 18: 921-37.

4 Falchuk ZM. Update on gluten-sensitive enteropathy. Am J Med 1979; 67: 1085-96.

5 Guix M, Skinner JM, Whitehead R. Measuring intraepithelial lymphocytes, surface area, and volume of lamina propria in the jejunal mucosa of coeliac patients. Gut 1979; 20: 275-8. 
6 Marsh MN. Studies of intestinal lymphoid tissue. III. Quantitative analyses of epithelial lymphocytes in the small intestine of human control subjects and of patients with celiac sprue. Gastroenterology 1980; 79: 481-92.

7 Dunnill MS, Whitehead R. A method for the quantitation of small intestinal biopsy specimens. J Clin Pathol 1972; 25: 243-6.

8 Mavromichalis J, Brueton MJ, McNeish AS, Anderson CM. Evaluation of the intraepithelial lymphocyte count in the jejunum in childhood enteropathies. Gut 1976; 17: $600-3$.

9 Ferguson A, McClure JP, Townley RRW. Intraepithelial lymphocyte counts in small intestinal biopsies from children with diarrhoea. Acta Paediatr Scand 1976; 65: 541-6.

10 Glasgow JFT, Corkey CWB, Molla A. Critical assessment of small bowel biopsy in children. Arch Dis Child 1979; 54: 604-8.

11 De Peyer E, France NE, Phillips AD, Walker-Smith JA. Quantitative evaluation of small intestinal morphology in childhood. Acta Pediatr Belgica 1978; 31: 173 .
12 Croft DN, Loehry CA, Creamer B. Small-bowel cell-loss and weight-loss in the coeliac syndrome. Lancet 1968; 2: 68-70.

13 Wright N, Watson AJ, Morley A, Appleton D, Marks $\mathrm{J}$, Douglas AP. Cell kinetics in flat (avillous) mucosa of the human small intestine. Gut 1973; 14: 701-10.

14 Douglas AP, Weetman AP, Haggith JW. The distribution and enteric loss of ${ }^{51} \mathrm{Cr}$-labelled lymphocytes in normal subjects and in patients with coeliac disease and other disorders of the small intestine. Digestion 1976; 14: 29-43.

15 Marsh MN. Studies of intestinal lymphoid tissue. V. The cytology and electron microscopy of glutensensitive enteropathy, with particular reference to its immunopathology. Scand J Gastroenterol 1981; 16: suppl 70: 87-106.

16 Selby WS, Janossy G, Jewell DP. Immunohistological characterisation of intraepithelial lymphocytes of the human gastrointestinal tract. Gut 1981; 22: 169-76.

17 Selby WS, Janossy G, Goldstein G, Jewell DP. T lymphocyte subsets in human intestinal mucosa: the distribution and relationship to MHC-derived antigens. Clin Exp Immunol 1981; 44: 453-8. 